\title{
LOS INFINITIVOS EN EL CONJUGATIONSSYSTEM DE FRANZ BOPP*
}

\section{THE INFINITIVES IN FRANZ BOPP'S CONJUGATIONSSYSTEM}

\author{
José Luis García RamóN \\ Center for Hellenic Studies, Washington - Harvard University \\ garcia.ramon@uni-koeln.de
}

DOI: $10.1387 /$ veleia.16821

\begin{abstract}
Resumen: En el marco de la presentación de la conjugación verbal de cada una de las lenguas tratadas en su Conjugationssystem (sánscrito, griego, latín, persa medio y moderno y lenguas germánicas), Franz Bopp también se centra en las formas de infinitivo. En este artículo se presentan las ideas de Bopp sobre la morfosintaxis del infinitivo de las lenguas tratadas y se valora su aportación desde la óptica de lo que la Lingüística Indoeuropea permite asumir a día de hoy.

Palabras clave: Franz Bopp, Lingüística Indoeuropea, Lingüística Comparada, reconstrucción lingüística, morfosintaxis verbal, infinitivo.
\end{abstract}

Abstract: A part of the analysis of the verbal conjugation in each of the languages considered (i.e. Sanskrit, Greek, Latin, Middle and Modern Persian and the Germanic languages) by Franz Bopp in his Conjugationssystem is the study of the infinitival forms. The present contribution sets forth Bopp's views on the morphosyntax of the infinitives in the languages he deals with and evaluates his achievements from the point of view of current Indo-European linguistics.

Keywords: Franz Bopp, Indo-European linguistics, comparative linguistics, linguistic reconstruction, verbal morphosyntax, infinitive.

Recibido: 20-06-2016

Informado: 01-07-2016

Definitivo: 14-07-2016

\footnotetext{
* La presente contribución se basa en los materiales para el volumen Syntax V/3. Verbalsyntax: Infinitiv de la Indogermanischen Grammatik, fundada por Jerzy Kuryłowicz (Dr. Carl Winter Verlag, Heidelberg). Agradezco a Sergio Neri (Jena) sus comentarios sobre la supuesta forma ant. ingl. sceoldan (nota 41). Las interpretaciones propuestas en este trabajo se encuentran en lo esencial en García Ramón 1997 y (en prensa 1).

Convenciones: Formas de lenguas concretas citadas en la obra de Bopp en alfabeto latino (sin cursiva) se reproducen en cursiva (las sánscritas, además,
}

en transliteración actual: en algunos casos se cita en nota la transliteración original). Igualmente se reproducen en cursiva los términos gramaticales que en la obra de Bopp, en alfabeto gótico, aparecen en alfabeto latino (e.g. verbum, indeclinabilia: verbum, indeclinabilia). Sufijos y desinencias son reproducidos de acuerdo con las convenciones actuales, con guiones (e.g. -tum, $-\varepsilon v \alpha 1 . .$.$) que faltan en el original. Las citas literales y$ traducciones de Bopp se reproducen con comillas dobles. Se corrigen asimismo algunas erratas, especialmente en las formas griegas. 
1. En Das Conjugationsystem de Franz Bopp los infinitivos son estudiados en el marco de la presentación de la conjugación verbal de cada una de las lenguas tratadas (sánscrito, griego, latín, persa medio y moderno, lenguas germánicas) ${ }^{1}$, comenzando obviamente por el sánscrito, que es al fin y al cabo el punto de partida de la obra. En los apartados dedicados a cada lengua se aprecia una ponderada combinación de filología y reflexión teórica y, aunque no hay un capítulo dedicado a la comparación sistemática, ni mucho menos a la reconstrucción indoeuropea, hay alusiones ocasionales a las coincidencias con el sánscrito en las páginas dedicadas al griego, al latín y a las lenguas germánicas. La presentación en cada lengua se ajusta en gran medida a un mismo esquema, lo cual refleja tanto el intento de establecer una tipificación de los infinitivos sobre la base de los datos tratados por separado, como el de comparar y, en última instancia, reconstruir. Además, la recurrente atención a la comparación con el árabe se mueve en parámetros tipológicos avant la lettre, con la particularidad de que Bopp no entra a discutir si las lenguas semíticas y las indoeuropeas eran retrotraíbles a una protolengua común ${ }^{2}$.

Es innecesario insistir en que la labor pionera de Bopp en Conjugationssystem partía lastrada por una serie de limitaciones, que no eran sino las de su época. Ante todo, el operar con una nómina de lenguas muy reducida y, además, de diversa entidad y cronología: sánscrito clásico (pero no védico), griego y latín literarios (pero no textos epigráficos, ni lenguas itálicas), persa moderno (pero no antiguo) y lenguas germánicas. Ello es particularmente de lamentar en el caso de las formaciones de infinitivo. Por una parte, el material indoiranio se limita al infinitivo en -tum del sánscrito clásico, que en védico era todavía un supino coexistiendo con una serie de infinitivos plenos o in fieri, y a los en -tan del persa medio y moderno, que de hecho continúan los en /-tanail o /-tani/ del antiguo persa: quedan fuera de consideración el material del védico y avéstico en su totalidad, así como el antiguo persa. Quedan también fuera de consideración las inscripciones dialectales griegas y las latinas, así como las lenguas itálicas. Igualmente, las lenguas bálticas y eslavas, o el armenio (que aún no había sido reconocido como lengua independiente), al igual que osco y umbro, cuyo material es incorporado en la Vergleichende Grammatik de $1868^{3}$.

Ello no puede, naturalmente, considerarse demérito de Bopp, sino mero reflejo de las limitaciones del material conocido en su época para el desarrollo de una ciencia que estaba literalmente en sus comienzos. El punto de partida y las posibilidades de Bopp al escribir su Conjugationssystem eran mucho más limitados que los de Vergleichende Grammatik, escrita en el periodo en el que la nueva disciplina se iba asentando definitivamente, $y$, por supuesto, que las de las grandes síntesis de Brugmann, Delbrück o Meillet. De hecho, en una disciplina que ha evolucionado sensiblemente desde 1816, a medida que se ha ido ampliando el elenco de lenguas objeto de estudio y se han ido afinando los métodos de análisis y los aspectos teóricos, la síntesis de Bopp puede apreciarse en sus logros aún actuales y, además, ser ampliada sobre la base de lo que sabemos hoy acerca de los hechos que trató en su día.

En el caso concreto de los infinitivos, una reconsideración es necesaria (y está directamente condicionada) por dos razones. Por una parte, el carácter de nombre verbal que Bopp reconocía como originario en el infinitivo, con ser cierto, debe ser precisado: de hecho, el concepto mismo de infinitivo debe ser delimitado respecto al de forma casual de nombre verbal y al de quasi-infinitivo $(\$ 3.2)$. Por otra parte, los formantes ${ }^{*}-m e n-y^{*}$-ten- o la forma subyacente en el enigmático - $\alpha$ del

1 CS 37ss. (sánscrito), 70ss. (griego), 107ss. (latín), 132ss. (persa y germánico).

2 La cuestión se planteó decenios después, en particular en los orígenes de la teoría de las laringales.
3 VG 249ss. (véd. -tave, -tavái), 266s. (véd. -(a)dhyai, presentado como "dativo de un tema abstracto femenino"), 269s. (véd. -(a)se), entre otros. 
griego, que Bopp trató y consideró como muy antiguos, si no originarios, están atestiguados en las lenguas anatolias $(\$ 7):{ }^{*}-m e n-$ en abstractos (hit. -man-, luv. cun. -mman) y en el llamado "gerundivo" del luvita jeroglífico en -mina; ${ }^{*}$-ten- en abstractos (heteróclitos: hit. -tar/n-, luv. cun. -ttar/n) $\mathrm{y}$ en infinitivos (hit. -anna de $\left.{ }^{*}-\bar{a}-t n-\breve{a}\right)$, mientras que la desinencia de caso "adlativo" en -a /a(:)/, también presente en el infinitivo luvita en -una es, con toda probabilidad, inseparable de la forma subyacente en gr. - $\alpha \mathrm{l}(\$ 8)$. La prehistoria de estas formaciones puede y debe ser reconsiderada a la luz del testimonio de las lenguas anatolias y, en la medida de lo posible, de la distinción entre proto-indoeuropeo (incluyendo el anatolio) y lo que se ha llamado "Core Indo-European" o "Restindogermanisch" (IE reconstruible con posterioridad a la separación de las lenguas anatolias). Lo mismo cabe decir de las formaciones subyacentes en gr. - $\varepsilon v v(\mathrm{y}-\varepsilon v)$, - $\varepsilon v \alpha l$, concretamente ${ }^{*}$-sen- (y *-es-en), *-uen-, presentes en anatolio en abstractos (hit. -eššarl-ešn-, -uar/n-, luv. -uarl-un-) e infinitivos (luv. - una, lic. -na), que Bopp no podía conocer a la luz de los datos de que disponía (\$7).

Una relectura del trabajo de Bopp desde la perspectiva de nuestro tiempo permitirá valorar su mérito y actualizar nuestro conocimiento de los puntos que trató. En lo que sigue se intentarán integrar los logros de Bopp en cada capítulo en lo que sería su sistema, más bien que glosarlos siguiendo su orden de presentación por lenguas concretas: una serie de Addenda (Add.) precisará en cada caso lo que una perspectiva actual puede aportar. Se tratarán pues, por este orden, el concepto mismo de infinitivo $(\$ 3)$ y sus funciones $(\$ \$ 4,5)$, los formantes y desinencias casuales atestiguados en las lenguas tratadas en Conjugationssystem (\$6), así como los infinitivos formados mediante

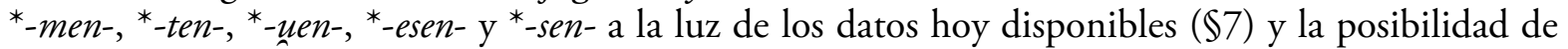
una conexión entre gr. - $\alpha$ y anatolio /-a(:)/ (\$8). No se entrará, en cambio, en el problema general de la reconstrucción de la situación en indoeuropeo, ni en la posibilidad de establecer una diferencia entre infinitivos (limitados a la función de complemento/actante) y converbos (adjunto libre / circunstante) $)^{4}$.

2. La síntesis de Bopp, que se mueve en el marco teórico del análisis de la lengua como organismo ${ }^{5}$, parte de la idea subyacente en toda la obra, de que las divergencias entre lenguas se deben a procesos de renovación formal y de contenido en cada una de ellas que dan lugar a un nuevo organismo, sin que ello suponga la renuncia a reconstruir los elementos heredados de una protolengua:

"es necesario que trabemos conocimiento ante todo con el sistema verbal de las antiguas lenguas indias, a continuación seguir con el de las lenguas griega y romana, con el de la lengua germánica y persa, mediante lo cual veremos su identidad, y al mismo tiempo reconoceremos la paulatina y gradual destrucción del organismo lingüístico elemental y la tendencia a susbsituirlo mediante conexiones mecánicas cuando sus elementos ya no son reconocibles y surge la imagen de un nuevo organismo"6.

${ }^{4}$ En el sentido de Haspelmath (1987), Stüber (2009, 2011) y Zehnder (2011). La distinción es, a mi modo de ver, superflua en el caso de los infinitivos de las lenguas IE.

5 Sobre la dualidad entre esta concepción y la historia de la lengua como parte de la Kulturgeschichte en que se mueve Bopp, cf. Bologna 1992, 2016.

6 "... ist es nothwendig, uns vor allem mit dem Conjugationssystem der altindischen Sprachen bekannt zu machen, sodann die Conjugation der griechischen und römischen, der germanischen und persischen Sprache vergleichend zu durchgehen, wodurch wir deren Identität einsehen, zugleich aber die allmählige und stufenweise Zerstörung des einfachen Sprachorganismus erkennen und das Streben beobachten werden, denselben durch mechanische Verbindungen zu ersetzen voraus, als deren Elemente nicht mehr erkannt wurden, ein Schein von neuem Organismus entstand" (CS 10-11). 
Se insiste, además, en que el objetivo del estudio es mostrar cómo ha surgido la aparente diferencia de una lengua respecto a otras que proceden de la misma lengua madre ${ }^{7}$. La idea de que la evolución implica renovación es crucial en el caso de los infinitivos, una categoría presente en todas las lenguas IE de antigua atestiguación para la que, sin embargo, la comparación no permite establecer correspondencias perfectas en más de dos lenguas que permitan retrotraer con certeza una (o varias) formaciones de infinitivo al indoeuropeo reconstruido. El asumir que la renovación formal puede ser responsable de la imposibilidad de reconstruir ecuaciones perfectas es un avance claro frente a la aplicación mecanicista del postulado meilletiano que exige para cada propuesta de reconstrucción una correspondencia en, al menos, tres lenguas. Igualmente lo es el intento de tipificación de las formaciones de infinitivo en cada lengua como paso previo a la comparación (así, el supino en -tum del latin con el infinitivo sánscrito en -tum, p. 114) y a la reconstrucción, si bien esta no se intenta sistemáticaente ${ }^{8}$.

El Conjugationssystem ha legado a la posteridad logros concretos, como el recurso a la conmutabilidad del infinitivo con formas casuales para la determinación de su función (\$5.1), la constatación de la concurrencia del infinitivo con otras formas nominales del verbo (concretamente en latín, $\$ 3$ ), la distinción entre sujeto/objeto lógico y sujeto/objeto gramatical y la interpretación de la estructura de las oraciones completivas con verbos declarativos y modales en griego y latín (\$5.2-3), el reconocimiento de la desinencia de acusativo en los infinitivos de las lenguas germánicas $(\$ 6.2)$ y la explicación de las conjunciones subordinativas como formadas sobre la base de relativos, y como artículo del verbo ("Artikel der Zeitwörtern”), en formulación paralela a la del artículo como introductor del infinitivo en griego clásico (\$ 5.5), así como, en un dominio marginal al estudio de los infinitivos, la interpretación de gerundios y absolutivos como antiguas formas de instrumental en sánscrito y en latín? . Asimismo, Bopp ha reconocido dos conceptos avant la lettre, concretamente el de gramaticalización de formas casuales como infinitivo, muy actual en los últimos ańos, para designar un proceso banal bien tipificado ya, por lo menos, desde Brugmann, y el de "conjunction reduction" de P. Kiparsky, aplicado al caso del inf. pres. latino utilizado para una acción pasada (cf. $\$ 3.1$ ), y válido asimismo para explicar formas adesinenciales como gr. - $\mu \varepsilon v$ o hit. -uuan $(\$ 6.3)$.

Forzoso es reconocer que algunas explicaciones de Bopp en 1816 son, vistas hoy, erróneas, como es comprensible habida cuenta del momento histórico y del contexto en que se formularon: así, la idea de que el formante ${ }^{*}$-men- (cf. los infinitivos en $-\mu \varepsilon v \alpha 1,-\mu \varepsilon v$ ) es el mismo que el del participio en *-meno- $(\$ 6.1)$, las interpretaciones de los infinitivos en $-(\varepsilon) v \alpha 1$ y $-\varepsilon 1 v(\$ 7)$, la de gr. - $\alpha$ l como forma casual correspondiente a un nominativo en ${ }^{*}-o-m(\$ 6.3)$ o la de germ. ${ }^{*}$-an (y $\left.{ }^{*}-\bar{n} n-\right)$ como variante de persa - $\tan (\$ 6)$. Sería ciertamente absurdo criticar unas ideas en las que más bien hay que apreciar el ingenio que revelan y el intento de integrar hechos sobre la base de lo (poco) que entonces se sabía de las lenguas con las que operar ${ }^{10}$.

7 "die scheinbare Verschiedenheit der lateinischen Conjugation von der des Sanskrits und des Griechischen" (CS 8-9).

8 Sí, en cambio, en la Vergleichende Grammatik, concretamente en el caso de véd. -se y gr. - $\sigma \alpha 1$, así como lat. $-r e,-r \bar{\imath}(V G 269$ ss.).
9 CS 43, 53ss. Igualmente lúcidos son los apartados sobre el instrumental propiamente dicho (44ss.) y los absolutivos védicos en $-t v \bar{a}-(C V 57)$.

10 También es erróneo presentar como particularidad la presencia o ausencia en sánscrito de - $i$ - (i.e. - $i$ tum, normalmente con grado pleno de la raíz frente a -tum), cf. bhavitum / bhutvā, navitum / notum (CS 58). 
3. El estudio del infinitivo en las lenguas tratadas en Conjugationssystem permite a Bopp establecer un sistema, que se concreta en los siguientes puntos:

3.1. La caracterización del infinitivo en las lenguas IE como (1) nomen actionis, indeclinabile, (2) rección coincidente con la del lexema/verbo personal, (3) en algunas lenguas mayor o menor participación en las categorías verbales, i.e. inserción en el paradigma verbal.

(1) La concepción del infinitivo como forma nominal ("Nomen"), y concretamente como "abstraktes Substantiv" o substantivum indeclinabile, por oposición a los participios (también "Nomen", pero adjetivo, con parcial adecuación a los temas temporales) aparece recurrentemente, en particular en los capítulos dedicados al sánscrito y al griego ${ }^{11}$ : así,

"der Infinitiv und die Partizipien werden zwar mit Recht von den indischen Grammatikern ... als Nomina betrachtet; nämlich ersterer als abstraktes Substantiv, letztere als Adjective, an denen besondere Zeitverhältnisse durch innere Umbiegung angedeutet werden können” (CS 37s.).

Bopp subraya que el infinitivo precedido de artículo ("pronomen demonstrativum”) en griego clásico $^{12}$ no hace sino caracterizar lo ya preexistente (i.e. su status de sustantivo, que se conserva a lo largo de la historia del griego) mediante una marca formal que en realidad no era necesaria ${ }^{13}$. El infinitivo griego nunca deja de ser un sustantivo ${ }^{14} \mathrm{y}$, además, presenta más empleos casuales que los que marca el artículo en griego clásico ${ }^{15}$. Su carácter de forma nominal pese a su integración plena en el paradigma verbal lleva a Bopp a rechazar el intento de reconocerle un status mixto a mitad de camino entre nombre y verbo, que a veces se le había atribuido y que considera una "criatura fantástica" ("ein solches phantastisches Geschöpf") que compara muy plásticamente con los centauros del mundo de la fábula ${ }^{16}$.

(2) Bopp menciona como característica del infinitivo (en sánscrito, pero con referencia al gerundio y supino, así como a los abstractos en -tiōn- del latín), el tener la misma rección que el verbo personal ("ser un abstracto que rige el mismo caso que el verbo finito de la misma raíz") ${ }^{17}$.

11 “ ... ein abstraktes Nennwort” (38), “Den griechischen Infinitiv halte ich für ein Substantivum indeclinabile (CS 70).

12 Hay un ejemplo dudoso en Homero, cf. Od.20.52/3

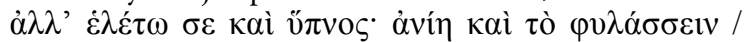

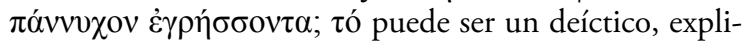
citado por $\varphi v \lambda a ́ \sigma \sigma \varepsilon i v$ ('... esto de estar de guardia').

13 "Als ... der Gebrauch des pronomen demonstr. als Artikel herrschend geworden, ward dasselbe dem Infinitiv, wie den anderen Substantiven vorgesetzt. Es ist aber nicht der Artikel, der ihm das Gepräge eines Substantivs gegeben hat, sondern er mußte Substantiv seinem Ursprunge und seinem frühern Gebrauche nach gewesen sein, um die Vorsetzung des Artikels zu rechtfertigen. Denn bei dem Infinitiv die Vorsetzung des Artikels nicht so nothwendig und allgemein wurde" (CS 70s.).

14 "so beweißt dieses, daß sich bei ihm in manchen Fällen die Construktion des Aelteren erhalten habe, er hört aber in solchen Fällen nicht auf, Substantiv zu sein" (CS 70s).
15 Cf. asimismo " $\mathrm{Zu}$ verkennen ist es jedoch nicht, daß sich im Griechischen das Gebiet des unbeugbaren Infinitivs mehr erweitert habe, als durch Deklination des Artikels, dessen Casusverhältnisse deutlich bestimmt werden konnten" (CS 71s.).

16 "So ein gemischtes Wesen von Substantiv und Verbum, das man dem Infinitiv angedichtet hat, ist überhaupt in keiner Sprache zu finden und es ist ein solches phantastisches Geschöpf den Centauren der Fabelwelt zu vergleichen..." CS 71).

17 “... ein abstraktes Nennwort, welches die durch Wurzel bezeichnete Handlung oder Eigenschaft ohne alle Nebenbestimmung ausdrückt, und sich in der Construktion nur darin von anderen Substantiven unterscheidet, daß es den Casus des Zeitwortes von derselben Wurzel regiert, worin es mit den abstrakten Nennwörtern, die im Arabischen die Stelle des Infinitivs vertreten, und mit dem lateinischen Gerundium und Supinum übereinstimmt, und den abstrakten Substantiven in tio gleicht, die von den Alten auch mit dem Casus des Zeitwortes von derselben Wurzel construirt wurden” (CS 38/9). 
La precisa formulación de Bopp es la acertada, y ciertamente preferible a la de "rección nominal" (: genitivo) frente a "rección verbal" (: acusativo), que aún hoy en día es usual, y que se presta a confusión. En efecto, la rección en genitivo no es exclusiva de formas nominales (hay lexemas verbales que rigen genitivo o dativo) y, además, hay nombres verbales que pueden regir acusativo, como evocaba Bopp con alusión (por primera vez, si no me engaño) a los nombres de acción en -tiōn- del latín, que son continuadores formales de los heredados en *-ti-. Se observará que la misma situación que en latín (e.g. lat. quid tibi nos (ac.) tactiost ? '¿por qué nos tocas?' Plaut $A u l$. 423) se da en otras lenguas, cf. véd. sátau vájam 'en la obtención (săti-) del premio (ac.)' $(\mathrm{RV} 7.36 .8)^{18}$.

(3) El diferente grado de integración de los infinitivos en el sistema verbal de cada lengua, i.e. en sus categorías flexivas, permite a Bopp distinguir al menos dos grupos de lenguas. Por una parte, griego y latín (un infinitivo por cada tema verbal y diátesis ${ }^{19}$ ). Por otra, sánscrito, persa moderno y lenguas germánicas, cuyos infinitivos son indiferentes a dichas categorías: sánscr. -tum expresa la acción verbal de la raíz sin otra precisión ${ }^{20}$, y en estas lenguas el infinitivo no expresa noción temporal $\mathrm{y}$, al menos en germánico, tampoco diátesis ${ }^{21}$. Bopp subraya, en todo caso, que

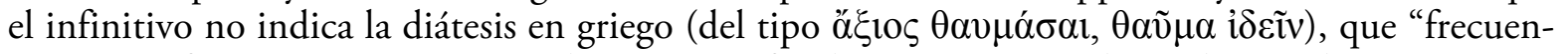
temente infinitivos activos son usados con significado pasivo"22 y en latín el tema de presente (no marcado), cuando el contexto deja en claro que se trata de una acción pasada, por una variante de "conjunction reduction", e.g.Ter. Andr. 429 ego illam vidi: virginem forma bona / memini videri ${ }^{23}$.

3.2. La delimitación del concepto de infinitivo frente a otras formaciones (supino, gerundio: declinabilia) impresiona por su precisión y agudeza, y no solo por la época en que se formuló. En dos puntos la aportación de Bopp es precursora de conceptos que han tardado en imponerse e incluso son aún ignorados en algunos estudios recientes, concretamente (1) las diferencias respecto a quasiinfinitivos, (2) la conmutabilidad en algunos contextos de infinitivos con supinos y gerundios en el interior de una misma lengua o entre lenguas diferentes (las llamadas correspondencias "heterogéneas", cf. infra).

(1) La distinción entre el infinitivo ("nomen indeclinabile") y el gerundio o el supino ("declinabilia"), que Bopp establece en el caso concreto del latín, es crucial y puede ser precisada en el detalle (cf. infra Ad (1)). Bopp subraya como característica del gerundio y del supino, como también

${ }_{18}$ La expresión del objeto en acusativo tanto en el infinitivo como en el participio se explica bien por la influencia del verbo personal, como también ocurre con otros nomina actionis (e.g. káma-: mám ... kámena AV 6.9.1) y con los nomina agentis en -tar- (e.g. hántā yó vrtrám sanitotá vájam 'matador de Vrtra-, ganador del premio' RV 10.61.9).

19 Ello se debería, según Bopp, a que el infinitivo se forma a partir del participio ("Die Entstehung des griechischen Infinitivs aus den Partizipien ist wohl die Ursache, warum gleich den Partizipien tempus und genus zu verändern fähig sind" (CS 87).

20 " ... ein abstraktes Nennwort, welches die durch Wurzel bezeichnete Handlung oder Eigenschaft ohne alle Nebenbestimmung ausdrückt" (CS 38).
21 "der Infinitiv ist im Persischen und in den germanischen Mundarten ... immer Substantiv, und stimmt in soferne mehr als der griechische und lateinische, mit dem indischen ... überein, als an ihm keine Zeitverhältnisse angedeutet werden, und als er, wenigsten im Germanischen, unter demselben Form aktivischer und passivischer Bedeutung fähig ist" (CS 132s.).

22 "von der Fähigkeit den gegebenen oder erlittenen Eindruck durch die Form des Wortes anzuzeigen, wird auch bei dem griechischen Infinitive nicht immer Gebrauch gemacht, und es werden oft aktivische Infinitive mit passivischer Bedeutung gesetzt" (CS 87).

23 (En Bopp con v.l. videre) "Infinitivus praesens mit vergangener und zukünftiger Bedeutung ..., wenn die Construktion des Satzes über dessen Bedeutung keinen Zweifel lassen" (CS 113). 
del infinitivo del sánscrito (y del árabe), la indiferencia a respecto a las categorías diátesis (como todos los abstractos verbales) y tiempo ("besondere Zeitbestimmungen") 24 .

(2) la conmutabilidad del infinitivo con supino y gerundio en latín, que serían en origen poco o nada diferentes ("ursprünglich wenig oder gar nicht im Gebrauch verschieden") y pueden utilizarse "arbitrariamente" ("das eine für das andere willkürlich") en algunos contextos para expresar la misma función o un idéntico estado de $\operatorname{cosas}^{25}$. Dentro de la brevedad de las páginas dedicadas al tema, Bopp invoca dos ejemplos del empleo de infinitivo en lugar de ad+gerundio (Terencio) y de ac. -tum (Plauto) en los que en época posterior "la regla prescribía el uso del infinitivo" ("wo späterer Sprachgebrauch den Infinitiv vorschrieb”):

Ter. Andr. 55-57 quod plerique omnes faciunt adulescentuli, ut animum ad aliquod studium adiungant, aut equos alere aut canes ad uenandum aut ad philosophos

Plaut. Cist. 33 eas si adeas, abitum quam aditum malis

La formulación debe relativizarse: la concurrencia de las construcciones en latín, al menos en algunos contextos, no depende ciertamente de la cronología de los textos, y no parece posible suponer que una de las formaciones sea más antigua que las otras, ya que las tres están atestiguadas desde los primeros testimonios, lo que hace difícil - por no decir imposible - suponer que una forma de las atestiguadas es la única heredada. Se observa en todo caso que el infinitivo alere tiene una función final que no sería propia de su desinencia de locativo $\left({ }^{*}-i\right)$ : la forma no se corresponde con la función, lo que caracteriza a un infintivo sensu stricto. En cambio, el gerundio (ad) uenandum y los nombres de acción en -tum reflejan la función esperable en la forma de acusativo (directivofinal en el primer caso, objeto en el segundo): la forma se corresponde con la función, lo que es característico de lo que llamamos "quasi infinitivos" (cf. $A d(1)$ ). En latín, la diferencia entre supino (solo ac. -tum, ablat. $-\bar{u},-u \bar{\imath}$ [originariamente dativo]) y los nombres de acción en -tu- (¡flexión completa!) no es siempre reconocible, como no lo es en alemán actual entre das Ankommen y die Ankunft, especialmente como complemento de verbos de movimiento hacia adelante, que rigen acusativo, así primus cubitu surgat, postremus cubitum eat (Cato, de re rust. 5.5) "Der Erste erhebe sich vom Liegen, der Letzte gehe zu liegen" (CS 112).

Los dos puntos establecidos por Bopp pueden ser precisados en algunos aspectos ${ }^{26}$ :

Ad (1): La definición misma de (a) infinitivo sensu stricto de Bopp es la más acertada: forma única (indeclinabile) y aislada de todo paradigma, con desinencia (formalmente reconocible como casual) o terminación irreconocible como desinencia (e.g. gr. $-\alpha$ o $-\mu \varepsilon v$, o véd. -(a)dhyai) de un tema nominal productivo en la lengua en que se atestigua, y cuyas funciones no coinciden con la de la terminación (no se puede decir desinencia) del infinitivo: esquemáticamente, Forma $\neq$ Función, en lo sucesivo $\mathrm{F} \neq \mathrm{F}$ ).

Es clara la diferencia con (b) los nombres de acción (diversas formas casuales en paradigma vivo, todas con su correspondiente función: esquemáticamente $\mathrm{F}=\mathrm{F}$ ), e.g. lat. conuentus, o véd.

24 "Ersterer is ein nomen indeclinabile, letztere sind declinabilia und stimmen außerdem noch in sofern mehr mit dem indischen und arabischen Infinitive überein, als sie, wie diese, unter derselben Form aktivische und passivische Bedeutung haben können, gleich allen abstrakten Nennwörtern, und als an ihnen keine besondere Zeitbestimmungen angedeutet werden" (CS 112).
25 "Bei älteren Schriftstellern finden sich häufiger Spuren, daß Infinitiv, Gerundium und Supinum ursprünglich wenig oder gar nicht im Gebrauch verschieden gewesen, und daß das eine für das andere willkürlich gesetzt werden konnte" (CS 113).

26 García Ramón 1997, 47ss. 
gántu-, lat. conventiōn- o véd. gatí-, y con (c) los supinos y gerundios (también los de otras lenguas IE que Bopp no trata), que tienen en común la existencia de más de una forma casual (aunque no de un paradigma completo), que básicamente coinciden con su función: representan una categoría intermedia que podemos etiquetar como quasi-infinitivo (formas aisladas con desinencias plenamente reconocibles, paradigma incompleto, pero función coincidente con sus desinencias, i.e. $\mathrm{F}=\mathrm{F}$ ) por oposición a (a) los infinitivos sensu stricto y a (b) los nombres de acción. Es, por ejemplo, el caso de véd. dāváne que, pese a ser forma aislada, con sufijo obsoleto -van- permite reconocer una desinencia de dat. $-e\left({ }^{*}-e i\right)$ que se ajusta a la función de la forma, que es siempre final, o de dátave 'para dar' (dat. *-teu-eî) siempre final, junto a dátum (ac. *-tu-m) y dātób (gen.abl. *-téu-s) que expresan siempre dirección y origen respectivamente. El que en la bibliografía actual se siga mencionando como infinitivos estas formaciones ${ }^{27}$ no es ciertamente un progreso respecto a Bopp. La distinción entre (a) infinitivo, (c) cuasi-infinitivo y (b) nombre de acción / abstracto verbal se revela como indispensable a todos los niveles y permite, desde luego, reducir la desorbitada lista de supuestos infinitivos que se atribuyen al védico y al avéstico (lenguas a las que se les atribuye un número de infinitivos superior al del resto de las lenguas en su conjunto) a sus justas proporciones.

$A d$ (2): La existencia en el interior de una misma lengua de formas concurrentes para un mismo contenido y función, concretamente (a) un infinitivo y/o (c) un cuasi-infinitivo y/o (b) un nombre de acción / abstracto verbal ${ }^{28}$, tiene paralelo claro en la reconstrucción comparativa, en las llamadas correspondencias heterogéneas ("heterogene Entsprechungen" en la afortunada formulación de Strunk 1977).

Así, en la construcción como complemento de verbo de dirección [ir a X] (X: ac. [dirección]) se encuentra concurrencia de infinitivo y supino tanto en latín (Plaut. Bach. 631 uenerat ... aurum petere y Aul. 247 it petitum gratiam) como en védico (RV 5.43.8ab áchā mahí ... / gì̀r dutó ná gantv aśvina huvádhyai 'que el gran himno venga como un mensajero a invocar a los Aśvins', 1.164.4d kó vidvámsam úpa gàt práștum etát “¿quién se acerca al sabio, a preguntar esto?” Ello hace pensar que ambas construcciones son igualmente antiguas, al menos en las lenguas atestiguadas, y que se encuentran en oposición de inclusión: el supino (marcado) es conmutable con una parte del espectro del infinitivo (no marcado).

Igualmente, la construcción del tipo lat. horribile dictu el supino latino (Plaut. Bacch. 62 lepida memoratui 'cosas gratas de recordar') concurre con el gerundio (Varro, Re Rust. 1.23.6 loca ad serendum idonea) y, en otras lenguas, con el infinitivo (ant. hit. uškiziauanzi šanezzi 'grato de mirar' Ras Shamra 25.421:56, aav. vaç̄ srüidiiāi ... vahištzm 'la palabra mayor para escuchar' (Y. 45.5),

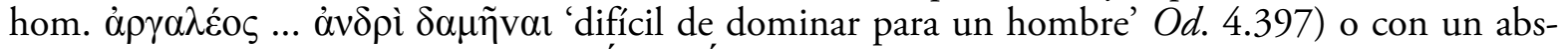
tracto verbal en dativo (RV 1.137.2 cárur rtáýy pìtáye 'grato de beber para el hombre justo’).

La reconstrucción de la situación en fases previas se enfrenta con problemas mayores: no hay argumento concluyente a favor de la existencia de infinitivos sensu stricto en indoeuropeo y, sobre todo, la prehistoria presupone procesos de renovación formal y funcional, que podemos suponer que fueron del tipo de los atestiguados en las lenguas concretas durante un periodo suficientemente amplio de tiempo, pero cuyo detalle es difícilmente aprehensible $-\mathrm{y}$ escapa, desde luego, a los límites de la presente contribución.

27 Así Gotō 2013, 136s.

28 También con participios y gerundivos, que no serán tratados en este punto. 
4. Siempre a partir de la concepción del infinitivo como forma nominal, de acusativo en el caso de sánscr. -tum, Bopp delimita dos funciones:

(1) la de objeto directo ("unmittelbares Objekt") con verbos modales como iṣ 'desear' (pres. icchá-), uṣ 'poder' (pres. ucchá-), arh 'deber', ejemplificada con jātum tvām vayam icchämah parafraseado como "conocerte nosotros queremos" ("Kennen (jätum) dich wollen wir"), que tendría equivalente en una frase latina del tipo "notum vel. notiorem te nos desideramus" o bien viprajukto hi Rāma na muhürtam api notsahe jīvitum munișārdūla, na Rāmam netum arhasi "separado de Rama no puedo vivir (jivitum) ni un momento, oh príncipe de los ascetas, no debes llevarte (netum) a Rama" ("geschieden von Rama einen Augenblick selbst kann ich nicht leben, o Fürst der Einsiedler, nicht den Rama nehmen sollst Du"). Como Bopp hace ver, los infinitivos en -tum son los objetos directos de los verbos modales icchämah, ${ }^{\circ}$ sahe, arhasi ${ }^{29}$.

$A d$ (1): Se observará que, de hecho, la interpretación es igualmente válida para las formas de infinitivo desarrollado en védico (entre otras, los en -adhyai, como también los en -diiäi, -uiiēe,... del avéstico), cuando son complemento del mismo tipo de verbos. El valor final que habitualmente se invoca para los infinitivos en ese caso está condicionado por el prejuicio teórico de que las formas de infinitivo son en su origen dativos, lo cual está en contradicción directa con el sentido más sencillo y la traducción menos forzada de los pasajes en cuestión. Así,

\section{RV 1.154.6ab tà vām vắstūni uśmasi gámadhyai 'a estas vuestras dos residencias deseamos llegar'30,}

en que el infinitivo gámadhyai es objeto de vaś, como lo es igualmente tád en RV 2.14.1d tád id eśá vașți 'esto es lo que él desea'. Igualmente, en antiguo avéstico e.g. 44.3 tācīt ... vasamì aniiācā vìduiiēe 'esas cosas y otras quiero saber (inf. vìduiiē /widwai/) 31 .

(2) la de "objeto alejado" ("entfernteres Objekt) o "segundo objeto" con función final ("als zweites Objekt..., der dasteht, um die Absicht zu begründen"), cuando depende de otros tipos de verbos que tienen un complemento directo (“... wenn die Wirkung der Handlung zunächst auf einen andern Gegestand fällt") o cuando es ampliación libre del predicado verbal. Así, en una frase del tipo dravyāni hartun tad grhan caurạ pravișta, que Bopp traduce como "para coger cosas en esta casa un ladrón entró" ("Habschaften zu holen trat ein Dieb in dessen Haus" VS 41): Bopp precisa que el infinitivo hartum, que a su vez tiene un objeto (: dravyāni 'cosas, posesiones'), expresa el objetivo de 3. sg. pravișta, verbo de movimiento con dos complementos, el primero tad grhan (i.e., el lugar al que se entra), el segundo ac. hartum (i.e., la acción a la que se dirige el sujeto "die Absicht der Bewegung") 32 .

29 "in diesen Beispielen sind dschätum, dschivitum und naetum (: jätum, jivitum, netum) die unmittelbaren Objekte der Zeitwörter ... itschämah wir wunschen, utsahae ich vermag, arhasi du sollst" (CS 39s.)

${ }^{30}$ Así, "We wish to go to the dwelling places belonging to you two [=Viśnu and Indra], where there are ample-horned, unbridled cows" (Jamison-Brereton). Igualmente, "zu euren beiden Wohnstätten begehren wir zu gehen" (Witzel-Gotō), mejor que "Diese euer beider (: Indras und Visnus) Wohnsitze begehren wir, um (sie) zu erlangen"(Geldner).
31 "these (are) the very (things) I wish to know - and other (things)" (Humbach) "je veux savoir ces choses et d'autres encore" (Kellens-Pirart).

32 Es un tanto excesivo entenderlo como "pacientivo" ("Da ... das Wort, welches die Absicht der Bewegung ausdrückt, auch von derselbe affiziert wird, und in einem leidenden Verhältnisse zu derselben steht, so kann es mit Recht auch in Accusativ gesetzt werden, da die Accusativendung eigentlich ein leidendes Verhältnis andeutet" CS 41). 
Ad (2): se observará que, concretamente, la formación de nomen actionis en ac. *-tum es propia de la construcción, con securidad heredada, del acusativo IE como complemento de verbos de movimiento indicando dirección hacia un término, con o sin llegada al mismo (véd. eti práș̦tum 'va a preguntar', Lat. it petitum 'íd.', Lith. éidamas gúttu 'yendo a dormir', ant.esl. şnidoš ş se vidètr 'vinieron juntos a ver'. Se trata, en realidad, de una antigua estructura con dos acusativos de dirección, cf. RV 1.164.4d kó vidvámsam úpa gāt prásțum etát ‘quién se acerca al sabio a preguntar sobre esto?, Plaut. Mi.Gl. 442 eam ueni quaesitum 'he venido a ella, a preguntar', umbr. avez anzeriatu etu (i b10) "auēs obseruātum itō", con reinterpretación de eam, avez como objetos de los supinos quaesitum, anzeriatu respectivamente (Hettrich 1984, 87ss, cf. \$3. Ad. 2).

(3) Se subraya asimismo que el infinitivo puede depender, además de un verbo personal, de sustantivos y adjetivos del mismo lexema verbal ${ }^{33}$, con los que comparte la construcción, así en yadyatra kānane sthätum icchā vartati, que Bopp traduce "si domina el deseo (icchā) de permanecer (sthätum) aquí en el bosque" ("Wenn hier im Walde zu bleiben Verlangen obwaltet"): el inf. sthätum depende del nom. $i c c h \bar{a}$, como podría depender de $i c c h a t i,-s i$ 'desea(s)' como en una frase no atestiguada del tipo +yad icchasi sthätum "Wenn du verlangest zu bleiben" construida ad hoc por Bopp.

5. Recordemos algunos puntos subrayados por Bopp de la sintaxis del infinitivo griego:

(1) Presenta la doble función reconocida para sánscr. -tum como complemento directo y como expresión de la finalidad $(\$ 4)$ y como marginales otros empleos casuales bien atestiguados ya desde Homero ("als Nominativ oder Genitiv dürfte der Infinitiv kaum gefunden werden" CS 72). La función del infinitivo como objeto directo de la acción ("unmittelbarer Objekt der Handlung"

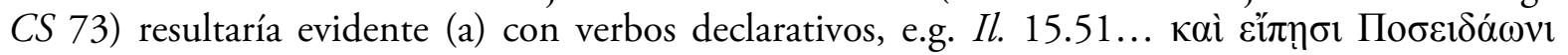

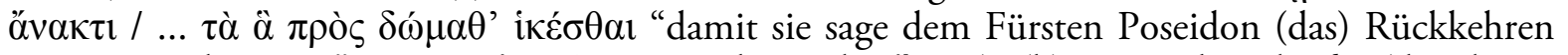

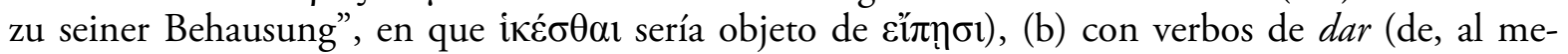
nos, dos posiciones: 'algo', 'a alguien' y una posible ampliación final 'para X'), e.g. Il. $1.337 \dot{\alpha} \lambda \lambda$ '

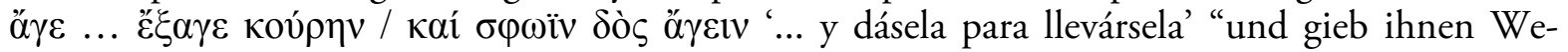

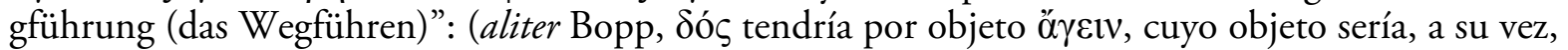

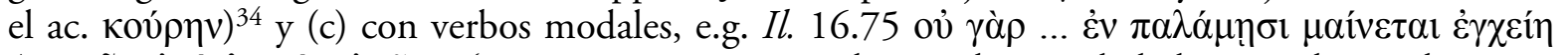
$\Delta \alpha v \alpha \tilde{\omega} v \dot{\alpha} \pi$ ò $\lambda$ oryòv $\dot{\alpha} \mu \tilde{v} v \alpha \imath$ '... en sus manos no se desea enloquecida la lanza rechazar el estrago de los Dánaos' (“...nicht wüthet, um abzuwehren”), en que ỏ $\mu \tilde{v} v a l$ es complemento del transitivo $\mu \alpha i ́ v \varepsilon \tau \alpha$. El análisis en sincronía es correcto y refleja en los tres casos el empleo como objeto directo de un infinitivo que precisamente no tienen forma reconocible de acusativo y que, una vez gramaticalizado, puede funcionar como complemento de verbos cuyo objeto es un acusativo o una completiva. No se trata, en todo caso, de una construcción heredada.

Ad (1): En el caso de los verbos de dar, el testimonio de lenguas que disponen de abstractos verbales para las funciones del infinitivo permite reconocer que el infinitivo griego (como el hitita o el antiguo eslavo) es conmutable con un dativo de nomen agentis o de supino, e.g. Il.18. 87

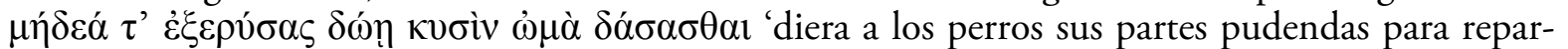
tir', KB 27.67 ii 42 adanna=ma=ta ÜZ-an pihhi 'pero te doy una cabra para comer', Mt. 27.34

33 "der Infinitiv steht auch nach Substantiven und Adjektiven, welche die Stelle von Zeitwörtern vertreten und als solche construirt werden" (CS 42).

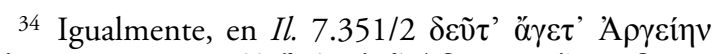

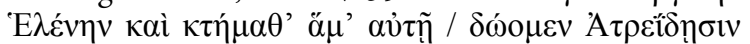
ă $\gamma \varepsilon 1 v$ “... laß uns geben den Atriden (das) Wegführen

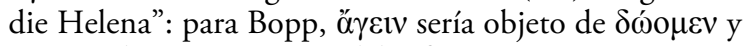

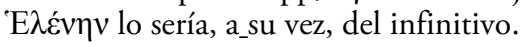




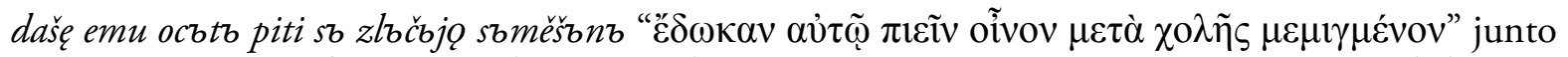
a Plaut. Most. 1086f. seruos ... dare suos mihi ... quaestioni, Cato Agr. 5,3 satui semen ... dederit nemini.

(2) En lo que es en sincronía la construcción de AcI, Bopp reconoce más bien dos objetos, de los cuales uno (el ac.) sería simplemente "sujeto lógico" del infinitivo, que, a su vez es objeto di-

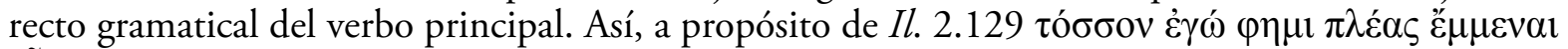
vĩas A $\chi \alpha 1 \tilde{\omega} v$, que Bopp traduce un tanto forzadamente "Um so viel sage ich, die Söhne der Achaier zu sein zahlreicher", subrayando que vĩa aparece en acusativo no por ser sujeto del infinitivo, sino porque es su sujeto lógico, no el gramatical ("bloß logisches, und keineswegs grammatisches Subjekt von "̌̈ $\mu \mu \varepsilon v \alpha \imath "$ (CS 75). Un análisis similar se aplica al latín, cf. Cic. Acad. 1.1 nuntiatum est nobis a M. Varrone eum venisse Roma, que Bopp parafrasea como "Es ward uns berichtet von Varro (ihn) in Betreff seiner gekommen zu sein von Rom", en que el infinitivo es entendido como "... entfernteres Objekt des Zeitwortes, somit als Akkusativ" 35.

(4) El infinitivo es utilizado como el acusativo de relación y el "dativo" homérico (en realidad, un instrumental) como muestra el recurso al criterio de conmutabilidad más allá de interpretacio-

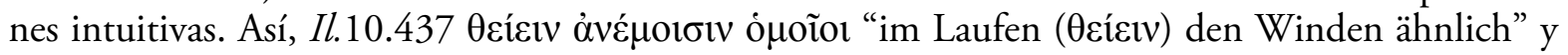

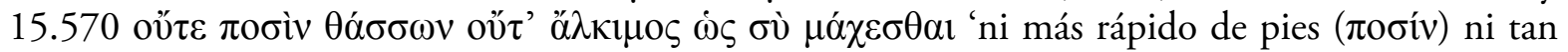

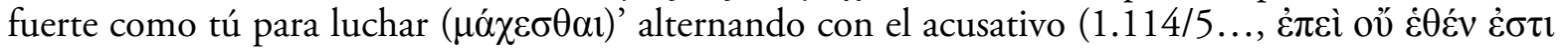

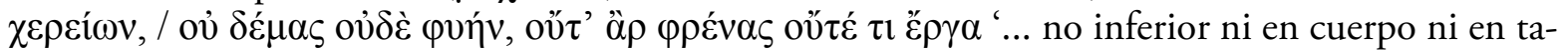

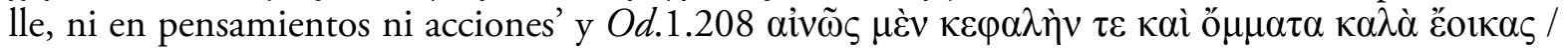
$\kappa \varepsilon \dot{v}(\omega)$.

Ad (4) recordemos que en Homero se atestiguan pares mínimos con un mismo verbo o adje-

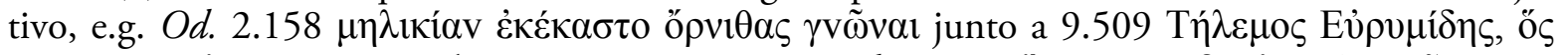

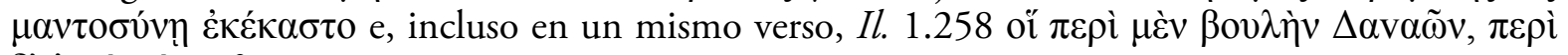

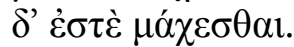

(5) Se constata la posibilidad del empleo del infinitivo en función de imperativo (ejemplificada

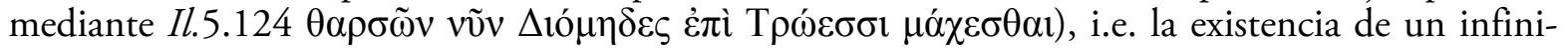
tivo en función impresiva y su commutabilidad con el imperativo ( $y$ con otros modos de la modalidad impresiva, como se ve en Rig Veda). Bopp intenta establecer una diferencia de función (la orden sería más expresiva con el infinitivo) ${ }^{36}$ que no resulta convincente pero, en todo caso, no menos que otros intentos más recientes: en realidad, el infinitivo, como forma no marcada de la oposición modal, puede ser conmutable con el imperativo sin diferencia apreciable de sentido.

(6) Siempre a partir de la idea de que el infinitivo tiene básicamente las funciones de un acusativo, recaracterizado por medio del artículo en griego clásico, Bopp presenta una ingeniosa explicación de las subordinadas como transformación de construcciones con infinitivo, en las que la conjunción haría la función del artículo (y se habría formado sobre un tema pronominal), que estaría en el caso correspondiente a la función del infinitivo o bien adoptaría una forma adverbial(izada) que le permitiría asumir otras funciones ${ }^{37}$.

35 Se aducen varios ejemplos en p.109 (tras un excurso sobre empleos similares del infinitivo en árabe).

36 "es widerspricht nicht der Natur des Infinitivs, als Substantiv, daß er zuweilen, eines besonderen Nachdrucks wegen, statt des Imperativ gesetzt wird" (CS 78s.).
37 "Nichts anders, als pronomina relativa oder demonstrativa sind wirklich die Conjuktionen welche die grammatikalischen Beziehungen des Infinitivs ausdrücken. Sie stehen entweder in dem Casus, der das auszudrückende Verhältnis bezeichnet, oder sie können unter einem adverbialischen Ausgange sämmtlichen Casusverhältnißen entsprechen (CS 79). 
En el marco de esta explicación, las conjunciones reflejarían la forma casual del infinitivo, o bien el tema pronominal sin desinencia, ampliado o no con partículas (CS 79s.). Así, ó $\imath$, que analiza correctamente como "ö -- $\tau$ ”" es explicado como acusativo neutro y como objeto de verbos del tipo 'decir' vel sim. ("ein Accus. neutr. und dann als Objekt der Zeitwörter stehen, die 'sagen', oder was ähnliches ausdrücken”), al que correspone lat. quod, así como alem. daß (por das), ingl. that y, en gótico, $p a-$ tei "Ő $\tau$ " (que es interpretado como "der Accusativ ungewissen Geschlechts des Relativs saei, sōei, patei --- qui, quae, quod”). En la misma línea, sánscr. yad corresponde a ö $\tau$ y es “... der Accusativ neutr. des Relativs ya-, yā, yad und ... einzig das grammatische Objekt des vorhergehenden Zeitwortes” y

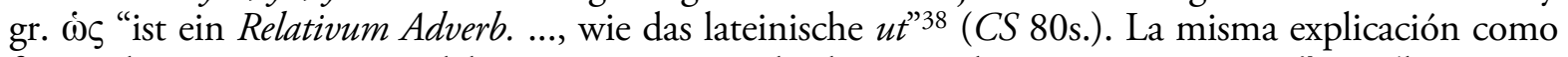
forma de acusativo neutro del tema *Hio-, seguido de partículas, se propone para ö $\varphi \rho \alpha$ 'hasta que, para que', cuyo demostrativo es correctamente reconocido en $\tau$ ó $\varphi \rho \alpha$, concretamente una partícula añadida "Anhängungspartikel $\varphi \rho \alpha$ " (CS 81s. $)^{39}$. La propuesta de Bopp de llamar a las conjunciones "artículo de las formas verbales" porque son para el verbo lo mismo que es el artículo para un sustantivo no flexionado ${ }^{40}$ no ha tenido continuidad, pero no deja de ser ingeniosa y, desde luego, tiene una coherencia interna con su visión de los infinitivos que, aun siendo parcial y dejando fuera de consideración algunos hechos mal conocidos en su época, es en muchos puntos acertada.

$A d(5)$ : Hom. ö $\varphi \rho \alpha$ es retrotraíble a ${ }^{*} H_{\lambda}$ io- $b^{h} r-t$, como hace ver O. Hackstein $(2005,182$ s.), que aduce un paralelo bastante exacto en tocario (A kupre 'cuando', kuprene 'íd.' de ${ }^{*} k^{u} i-b^{h} r$-en 'en el caso de que, cuando').

6. Pasemos a la morfología de las diferentes formas de infinitivo, también abordada lengua por lengua, sin intento sistemático de comparación ni reconstrucción, salvo en el caso del persa -tan, -ten, que intenta erróneamente, poner en conexión con germ. ${ }^{*}$-an $\left({ }^{*}\right.$-an-an) a partir de una pretendida forma base con ${ }^{*}-\tan _{-}{ }^{41}$, y con dos formaciones que, precisamente, no son específicas de infinitivo: es el caso, por una parte, del infinitivo sánscrito en -tum (que aún era supino en védico) y el supino latino en -tum y, por otra, el de gr.hom. $-\mu \varepsilon v,-\mu \varepsilon v \alpha$ l (y part. med. $-\mu \varepsilon v o \varsigma$ ), y -Evar (sic), que son puestos en relación con los participios del sánscrito en -māna- y -āna- respectivamente $^{42}$ y con referencia a la coexistencia de gerundivo -ndus y gerundio -ndum en latín. El infinitivo se habría formado mediante una pretendida sustitución de la desinencia de nom. -os por la "inmutable o adverbial desinencia $-\alpha \imath$ " 43 .

38 Errónea es la idea de que lat. ut esté emparentado con ita ("welches wahrscheinlich, wie ita von is, ea, id kommt, denn $u$ galt bei den alten oft für $i$ ").

39 Menos acertada es la explicación de îva: “... dem Accusativ des griechischen Infinitivs, der eine Absicht, einen Beweggrund ausdrückt, entspricht die Conjunction iv $\alpha$-- i $[$ sic por iv $\alpha$, i $\zeta$ ] halte ich für das ausser Gebrauch gekommene Relativ, welche das demonstrative $\tau \imath \varsigma$ erwarten läßt, und ǐv $\alpha$ wäre dann dessen Accusativ plur. neutr." (ibíd.).

${ }_{40}$ "Ich möchte diese Art von Conjunctionen lieber den Artikel der Zeitwörtern nennen, weil sie eigentlich bei Zeitwörtern gerade das vertreten, was bei unbiegsamen Substantiven der biegsame Artikel” (CS 82).

41 "Dass (scil. protogerm. *-an-) durch Abwerfung des $t$ oder $d$ aus tan oder dan entstanden sei, ist nicht ganz unwahrscheinlich, wenn wir in Erwägung ziehen, daß von der Wurzel sceol der Infinitiv sceol-dan sollen kommt" (CS 133). En realidad ags. sceold- es tema de pretérito con dental, no un tema de infinitivo de sceal (posterior scyl), sculon (sceolon, posterior -y-), pret. sceolde (cf. Seebold 1970, 406 s.v. SKAL 'schulden'): un infinitivo sceoldan no existe, y posiblemente es una ghost-form nacida de una interpretación errónea de la forma de pretérito en dental como derivado secundario (cf. alem. Schulden) (Sergio Neri, c.p.).

42 "hier müssen wir uns in das Gedächtnis zurückrufen, daß im Skr das part.med. in -māna- auch -āna- heißen kann und daß letztere Form denjenigen Zeitwörtern eigen, deren Wurzel nicht mit einem Vokal endigt, und die in der Conjugation nicht einem Vokal anfügen" (CS 85s.).

43 "Die Infinitive auf - $\mu \varepsilon v \alpha 1$ werden von der Stammsilbe auf dieselbe Weise abgeleitet als die particip. med. 
En realidad, la correspondencia entre $-\mu \varepsilon v,-\mu \varepsilon v \alpha \imath$ y part. $\mu \varepsilon v o \varsigma$, y entre estos y sánscr. part. -māna- y -āna- es solo aparente: inf. ${ }^{*}-m e n-$ refleja ${ }^{*}-m e n-$ mientras que part. ${ }^{*}-m e n o-(-\mu \varepsilon v o \zeta)$ refleja una formación distinta ${ }^{*}-m h_{1} n o$ - (véd. temát. -(a)māna-, atemát. -āna-). Ello invalida la idea de Bopp de que las formaciones de infinitivo se han creado a partir de las de participio, a las que se debería a su vez la inserción del infinitivo en las categorías verbales (\$3.1). En todo caso, solo cabe apreciar su mérito de insertar los hechos en un esquema coherente.

Recordemos lo esencial de las propuestas de Bopp sobre los formantes y formas casuales de las formas de infinitivo:

(1) En cuanto a los formantes, Bopp opera acertadamente con los abstractos en *-tu-para sánscr. -tum, y con los en ${ }^{*}-m e n-\mathrm{y}^{*}$-en-para el griego, así como ${ }^{*}$-ten- para el persa mod. -talen, y un "Nasalstamm" (con forma idéntica para nominativo y acusativo) para germ. ${ }^{*}$-an (*-an-an).

$A d$ (1): Una serie de formantes se atestiguan en más de una lengua, incluidas las anatolias, como infinitivo o quasi-infinitivo: es el caso de ${ }^{*}$-uen- $\left(\mathrm{de}^{*}\right.$-uer $/ n$-), ${ }^{*}$-ten- $\left(\mathrm{de}^{*}\right.$-ter $\left./ n-\right)$, *-men (no heteróclito: gerundivo luv. jerog. - mina). Otros sufijos se atestiguan como infinitivos o quasi-infinitivos en varias lenguas, pero no en anatolio, e.g. ${ }^{*}-s e n-\left(\right.$ probablemente loc. $\left.{ }^{*}-s-e n\right),{ }^{*}-e n-\left(\mathrm{de}^{*}-r / n-\right)$, ${ }^{*}$-es-, ${ }^{*}-t u-,{ }^{*}-t i-,{ }^{*}-d^{b}{ }^{i o-},{ }^{*}-i o-,{ }^{*}$-tio-. El hecho de que se atestigüen en más de dos lenguas autoriza a pensar que algunos de ellos pueden ser retrotraíbles al indoeuropeo posterior a la separación del anatolio ("Core Indo-European").

(2) En cuanto a las desinencias nominales, Bopp, en coherencia con su concepción del infinitivo como nomen verbale, reconoce acertadamente las de acusativo en sánscr. -tum (así como en el supino lat. -tum y gerund. -ndum $)^{44}$ y en germ. ${ }^{*}$-an (: gót. -an $)^{45}$, en realidad ${ }^{*}$-an-an, sobre el que observa que cuando se caracteriza por medio de una preposición *tō (: ant. ingl. to, aaa. zuo, ze, de instr. ${ }^{*} d o h_{1}$ ) que aparece en el caso que rige la misma (dativo: -e, e.g. ant. ingl. to forsvilanne 'para corromper' junto a forsvilan 'íd.' (cf. CS 110) ${ }^{46}$. Por otra parte, lat. -re es explicado a partir de * ${ }^{*}$ se ("amare für ama-se", "Statt ... edere findet man esse d.h. ed-se", CS 107), igualmente fore como reflejo de ${ }^{*} f u s e^{47}$, si bien no se entra en la cuestión de su forma casual (loc. ${ }^{*}-s-i$ ). No se entra tampoco a precisar la forma casual subyacente en los infinitivos del persa medio y moderno en -an, que son inseparables de antiguo persa (cf. pers. kandan 'cruzar' : ap. kantanaiy) (CS 132), continuador de ant. pers. -t-n-i-y/-tanil o /-tanail de un antiguo heteróclito en *-ter/n-, atestiguado también en anatolio. Entre las formaciones del griego, las que mayor atención reciben en su conjunto (CS 84ss.), Bopp reconoce como las más antiguas hom. - $\mu \varepsilon v \alpha$ y lo que presenta, anticipando la re-

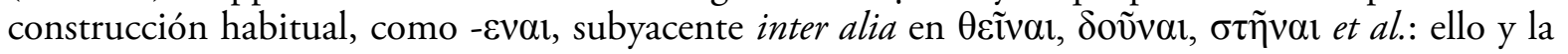

in - $\mu \varepsilon v 0 \varsigma$ : durch Anhängung der Silbe $-\mu \varepsilon v$-. Oder es wäre vielleichr richtiger, zu sagen, daß jene aus diesen entstanden seien, dadurch, daß die unveränderliche oder adverbialische Endung - $\alpha$ an die Stelle der Nominalendung os getreten sei; und daß so der griechische Infinitiv der Bildung nach mit dem lateinischen Gerundium zu vergleichen, welches aus dem part. in -ndus entstand" (CS 85).

44 "Fast durchaus läßt er sich als Accusativ betrachten, sei's nun, daß er das unmittelbare und nächste $\mathrm{Ob}$ ject des vorhergehenden Zeitworts ausdrücke, sei's, daß er mit dem regierenden Zeitworte in einer Beziehung stehe, die an dem germanischen Infinitiv durch die Präposition $z u$ ausgedrückt wird, im Sanskrit durch den
Infinitiv; im Lateinischen durch den Accusativ des Supinums oder Gerundiums..." (CS 72).

45 Así CS 133 (“... als Akkusativ ist daher der germanische Infinitiv größtentheils zu betrachten”).

46 Resulta, en cambio, sorprendente desde el punto de vista morfológico la interpretación de hom. ஸे $\sigma \theta \alpha$ i 'estar sentado' como "Accus. des Nomen indeclinabile"

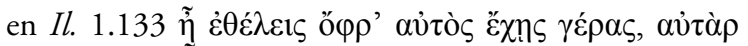

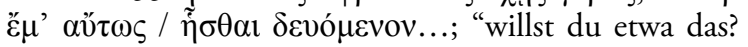
Du selbst habest Belohnung, was mich betrifft aber, (ein) Sitzen hier, dürftig!" (CS 81).

47 Menos afortunada es la explicación de fuisse a partir de *fu-esse (CS 94), que es más bien transponible como ${ }^{*} b^{h} u H-i s-s i$. 
existencia de nomina actionis en -man- y -an- en antiguo indio le permite insistir en el carácter nominal del infinitivo ${ }^{48}$.

Ad (2): Los diferentes infinitivos de las diversas lenguas permiten reconocer prácticamente todo tipo de desinencias casuales como forma de partida. Además del acusativo (germ. *-an(an) de *-onom, sabélico *-om, también en el supino de véd. -tum, lat. umbr. -tum, lit. -tu, ant.esl. -tъ), también, y en particular, el dativo (e.g. véd. -adhyai : ant. avest. -diiäi, lat. -ei, -ì, véd. -(a)se, celtib. -unei) y el locativo (véd. -sáni, lat. -re [*-s-i] y, con desinencia cero, gr. - $\mu \varepsilon v$, hit. -uuan, ant.esl. -ti de*-tēi-ø), quizá también ant. pers. -t-n-y/-tanil: ${ }^{*}$ ten- $i$ [o bien /-tanail: dat. ${ }^{*}-t^{\circ} n-e i$ ), el ablativo (hit. -uanzi, de variante en sandhi de ablat.-instr. *-uonti $V$-) y el instrumental (sabél. *-fié [osc. -fí-r, umb. $f(e) i)] \mathrm{de}^{*}-d^{h} i{ }^{2} h_{1}$, probablemente lat. arc. -ier de * $-i i e h_{1}+r$. Finalmente, el "adlativo" en las lenguas anatolias, cf. hit. -anna $\left({ }^{*}-\bar{a}-t n-\bar{a}\right)$, luv. -una, lic. -ña $\left({ }^{*}-u n-\bar{a}\right)$, así como el "gerundivo" luv. jerog. -mina $\left({ }^{*}-m n-\breve{a}\right)^{49}$. Los infinitivos anatolios son una innovación "einzelsprachlich" posterior a la separación del tronco común ${ }^{50}$ : las desinencias son exclusivas del anatolio (instr.-abl. *-ti, adlativo $-\bar{a})$, hit. -anna presupone un conglomerado ${ }^{*}-\bar{a}-t r / n-$, si bien la función de la desinencia $-\bar{a}$ $\left({ }^{*}-e h_{2}\right)$ puede ser heredada (cf. $\left.\$ 8\right)$.

(3) El formante - $\alpha \mathrm{l}$ del griego no es presentado como desinencia reconocible por Bopp, que habla de una "gemeinschaftlicher Infinitivendung - $\alpha \iota$ " y "unveränderliche oder adverbialische Endung - $\alpha \iota$ ", en formulación que sigue siendo actual hoy en día, pese a las numerosas interpretaciones propuestas en los últimos decenios. Particularmente interesantes son dos puntos que subraya Bopp $p^{51}$ : (a) la distribución de los formantes, con y sin - $\alpha$ l, se ajusta tendencialmente a la estructura de la raíz o tema verbal sobre el que cada infintivo se forma: así, Bopp intenta hacer ver que $-\mu \varepsilon v \alpha$ y $-\mu \varepsilon v$ se dan preferentemente en verbos en vocal (incluidos los temáticos) ${ }^{52}$. En la lengua homérica es imposible reconocer un criterio de distribución, pero en los dialectos, en particular en griego oriental, criterios como el carácter monosilábico o no del tema verbal juegan un papel, no coincidente por lo demás en todos los dialectos ${ }^{53}$. (b) la explicación de $-\mu \varepsilon v$ a partir de $-\mu \varepsilon v \alpha$ l por pérdida de $-\alpha$, si bien no indica en

48 “... so ist wohl für das Aktiv die Form in - $\mu \varepsilon v \alpha \imath$, die bei Homer so gebräuchlich, für die eigentliche und ursprüngliche zu halten. Mit den ... in $-\mu \varepsilon v \alpha$, glaube ich, daß in der ältesten Sprache deren in - $\varepsilon v \alpha r$ gebräuchlich gewesen. $-\mu \varepsilon v$ und $-\varepsilon v$ sind Nominalendungen [recte Nominalbildungen G.R.] und ist also der griechische Infinitiv schon seiner Bildung nach nomen" (CS 84-5). Menos exacta es, naturalmente, la formulación "Durch Anhängung von $\mu$ und $v$ an die Wurzel werden im Sanskrit und im Griechischen, Substantive und Adjektive gebildet" (ibídem). Los infinitivos en $-\mu \varepsilon v \alpha r$ "werden von der Stammsilbe auf dieselbe Weise abgeleitet als die particip. med. in - $\mu \varepsilon v o s:$ durch Anhängung der Silbe $\mu \varepsilon v "$ (CS 86).

49 Sobre ant. pers. -t-n-i-y cf. García Ramón 1997, 47; sobre hit. -uuanzi cf. Eichner 1973, 62, 92; sobre sabél. *-fiẹ cf. García Ramón 1993; sobre luv. jerogl. -mina cf. Melchert 2004, García Ramón (en prensa 2).

50 García Ramón (en prensa 3).

51 Otras interpretaciones, ciertamente ingeniosas, resultan infundadas hoy a la luz de nuevos datos y conocimientos que faltaban en época de Bopp. Así, Bopp

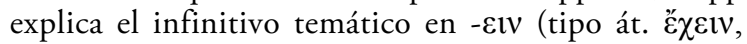

$\varphi \varepsilon ́ \rho \varepsilon \imath v)$ sobre la base de la existencia de - $\varepsilon v$ (en - $\varepsilon v \alpha 1$,

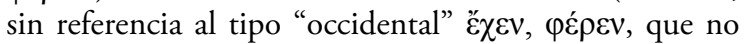
le era familiar) y por analogía con las formas personales en $-\varepsilon \varsigma,-\varepsilon$ de presente (dorio literario) junto a $-\varepsilon 1 \zeta,-\varepsilon$ : "aus $-\varepsilon v$ ward - $\varepsilon \imath v$, so wie in der zweiten Person praes. aus $\left.\varepsilon \imath \varepsilon \imath \varsigma^{\prime}\right)$ o la de medio-pasivo $-\sigma \theta \alpha \iota$ a partir de ${ }^{*}-\theta \alpha \imath$ (" $\tau u ́ \pi \tau \varepsilon \sigma \theta \alpha \imath$ st. $\tau u ́ \pi \tau \varepsilon \theta \alpha \imath$ "), sobre cuyo origen solo se nos dice que " $\varsigma$ verbindet sich gerne mit $\theta$, und es wird of dem part. in $\theta \varepsilon 1 \varsigma$ vorgesetzt".

52 "Mit dieser Regel hängen die griechischen Infinitive in $-\mu \varepsilon v \alpha 1$ und $-\varepsilon v \alpha 1$ oder $-\mu \varepsilon v$ und $-\varepsilon v$ zusammen, denn wir finden allerdings die Endung $-\mu \varepsilon v \alpha$ und $-\mu \varepsilon v$ vorzüglich" con aquellos verbos "deren Wurzel mit einem Vokal endigt, oder die in der Conjugation einen Vokal anfügen". Menos clara es la formulación que sigue: "Dagegen ist der Infinitiv in - $\varepsilon v$ (st. - $\varepsilon v \alpha \imath)$ den verbis barytonis besonders eigen" (86).

53 Se recordará que la distribución mecánica según tipos de verbo se da en otras lenguas. Así, en hitita - anna se da en verbos de la conjugación en -mi sin apofonía (e.g. adanna 'comer', appana 'alcanzar') y solo esporádicamente en otros tipos de verbos (e.g. uuanna 'ver' de una-hbi-). 
qué contexto o por qué razón pudo tener lugar ("Die Endung - $\alpha$ l konnte auch abgeworfen, und so $-\mu \varepsilon v$ für $-\mu \varepsilon v \alpha l$ gesetzt werden; von $\varepsilon v \alpha \iota$ hat sich die abgekürzte Form einzig erhalten" (cf. CS 85).

Ad (3b): De hecho, hom. '̌ $\mu \varepsilon v$ e 'í $\mu v v \alpha$ coexisten sin diferencia alguna de sentido en la perífra-

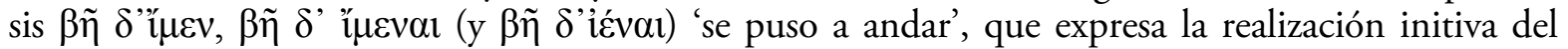
tema de aoristo con un verbo de lexema durativo. La eliminación (o, simplemente, la ausencia) de una marca formal es perfectamente concebible cuando factores, como el contexto o la construcción del verbo matrix, no dejan lugar a duda sobre la función del infinitivo, como es el caso de la perífrasis homérica mencionada supra, y hacen innecesaria la forma desinencial, por una especie de "conjunction reduction". Es, en efecto, la mejor manera, si no la única, de explicar hit. -uuan (*-uen-) frente a luv. jerogl. -una (adlativo $\left.{ }^{*}-u n-\breve{a}\right)$ en la perífrasis igualmente initiva hit. dai-l tiia- + X-uuan, luv. jerogl. $t \bar{a}+\mathrm{X}-u n a^{54}$ o frente $\mathrm{a}^{*}-u e n-a i$ /-ei (chipr. /dowenail, véd. -vane, -vani). Igualmente, el formante ${ }^{*}$-sen- $\varnothing$ (protogr. ${ }^{*}{ }^{h} e n$, mic. $/{ }^{h}$ en $/$ ) junto a ${ }^{*}-$ sen-i (infinitivos védicos en -sani).

7. Recordemos lo esencial desde una óptica actual en cuanto a los infinitivos tratados por Bopp en Conjugationssystem:

(1) IE *-men- se da en infinitivos sensu stricto (forma irreconocible, inasociable con la función) únicamente en griego: lesb. hom. - $\mu \varepsilon v \alpha \imath$ (hom. $\sigma \tau \eta ́ \mu \varepsilon v \alpha l, \delta o ́ \mu \varepsilon v \alpha \imath$, (F)'̌́ $\delta \varepsilon v \alpha \imath$ ) puede ser remodelación de dat. *-men-ei : véd. -máne), gr. occid., hom. - $\mu \varepsilon v$ (tipo $\sigma \tau \tilde{\alpha} \mu \varepsilon v, \delta o ́ \mu \varepsilon v)$ remonta a un locativo *-mén-Ø). El sufijo se atestigua también como nombre de acción (formante productivo, forma coincidente con la función), con paradigma completo en las lenguas anatolias (con la particularidad del "gerundivo" de luvita jeroglífico en -mina e.g. 30 OVIS ... DARE-mina 'treinta ovejas para entregar (= ser entregadas)' y en indo-iranio, en que los tipos véd. dámane 'para dar' (de dàman- 'donación', con gen. dámanah), vidmáne 'para saber' (de vidmán- 'conocimiento, con instr. vidmánā) representan dativos finales regulares de nomina actionis.

(2) IE *-ten- (de un antiguo heteróclito ${ }^{*}$-ter/n-) perfectamente representado como infinitivo en antiguo persa, al margen de la incertidumbre sobre su desinencia nominal: $-t-n-i-y$ que puede ser tanto -tanai (dativo) como -tani (locativo, *-tén-i), con función de complemento de verbos de movimiento (ay 'ir', aiš 'enviar', syav 'partir') y modales (dars 'osar', ni-stāy 'ordenar', tav 'poder) y posiblemente en véd. -táni en el hápax $p u p \bar{u}-t a ́ n i$ 'para purificarse' (: $p a v^{i} / p \bar{u}$ 'purificar'). El sufijo está bien atestiguado en anatolio como infinitivo en la forma hit. -(a)nna $<^{*}-(V) t n-\bar{a}$, adlativo de un nombre en $-(\bar{a})$ tar- (con paradigma completo: gen. -annaš, dat. -anni, abl. -annaza).

(3) El formante que Bopp reconstruye como *-en- (y -Eval) recubre en realidad diferentes tipos que, en su época, eran desconocidos y que subyacen en formas de infinitivo sensu stricto en anatolio, en védico, en celta y, especialmente, en griego: los heteróclitos en (a) *-uer/n- (anatolio, griego, hispanocelta), (b) *-r/n- (griego) y (c) ${ }^{*}-$ sen, loc. ${ }^{*}-s$-en de un tema en ${ }^{*}$-es- (védico, griego) que subyacen en formas de infinitivo en griego, así como en anatolio.

Respecto a (a) un infinitivo en *-uenai, asegurado en chipriota (to-we-na-i /dowenail como complemento de 3 pl. e-u-we-re-ta-sa-tu leuwrètasa ${ }^{(n)} t u /$ 'estuvieron de acuerdo en', en la tabla de Ida-

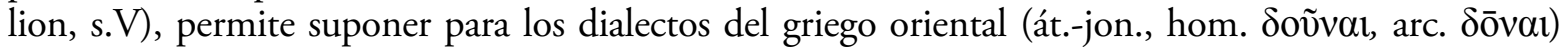
un *douenai, del que no quedaría resto por la temprana caída de /w/ intervocálico. El infinitivo en

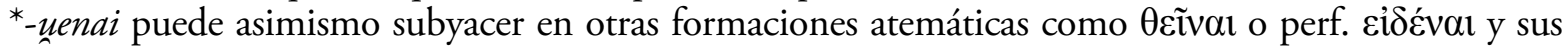
correspondientes en dialectos del griego oriental. Por su parte, *-uen- está bien atestiguado como in-

54 Sobre el luvita jeroglífico cf. Morpurgo Davies 1987, sobre el supino hitita cf. García Ramón 2007. 
finitivo en anatolio (hit. -uuanzi, luv. -una y muy probablemente en licio - $\tilde{V} n a-$ e.g [t]tãna 'poner' de *-ună (cf. Melchert 1994, 160) más bien que *-tnă), así como en el "supino" en -uuan (loc. -uén-Ø) y

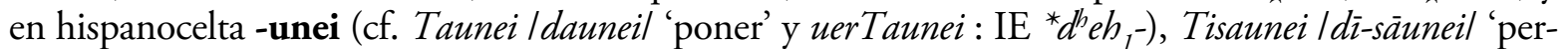
judicar' (cf. lat. sānus 'con salud') como complemento de verbo modal liTom 'está permitido' (Botorrita I. A2). En cambio, dat. *-uén-ei en védico (-váne) y avéstico (-uuanoi /-wanail) no son infinitivos sensu stricto ya que, si bien el morfema no es productivo en ambas lenguas, las formas del tipo véd. dāváne 'para dar' (y 'para recibir'), ant. avest. viduuanōi 'para saber' son siempre finales, que es justamente lo que se espera en un dativo. De hecho, las correspondencias véd. dāváne : chipr. /dowenail y ant. avest. /uiduanail : hom. eỉó́var (rehecho a partir de perf. *uid-uénai) son puramente formales, pero no en cuanto al estatus de cada forma (infintivo las griegas, quasi-infintivo las indoiranias).

Respecto a (b), cf. proto-gr. ${ }^{*}-e^{h} e n\left(: \mathrm{IE}^{*}\right.$-es-en reanalizado en el interior del griego como temá-

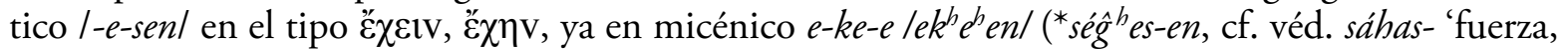
victoria', av. hazah-, gót. sigis "Vĩ $\varsigma$ "). El tipo de formación tiene correlato perfecto en abstractos verbales desarrollados en germánico (*-iz-an-: ant. saj. egiso(n) 'temor' junto a gót. agis " $\varphi o ́ \beta o \varsigma^{\prime}$ ", cf. ă $\chi 0 \varsigma)$ y en hitita en los heteróclitos en -eššarl-ešn-, gen. -ešnaš, dat.-loc. -ešni).

Respecto a (c), cf. los infinitivos mic. e-re-e levehenl 'remar' ( ${ }^{*} h_{1}$ erd $\left.{ }_{1}-s e n\right)$ y véd. tarișáni 'atravesar' ( $\left.{ }^{*} t^{2} h_{2}-\operatorname{sén}-i\right)$, ambos con estructura CeCH-sén(i). Protogr. - ${ }^{h} e n\left({ }^{*}-s e n\right)$ y véd. -sáni se corresponden perfectamente a partir de un locativo en ${ }^{*}-s-e n\left(\right.$ mic. $\left./{ }^{h}{ }^{h} n /\right)$ de un tema anfidinámico en *-es-, recaracterizado con -i deíctico (véd. -sani), como véd. jm-án : jm-án-i 'en tierra', mūrdhán: $m \bar{u} r d h a ́ n-i$ 'en la cabeza, en la punta'.

9. Para concluir, volvamos sobre el enigmático formante - $\alpha$ l, con su sorprendente vocalismo, de amplia extensión y diversa distribución en los infinitivos griegos, que puede clarificarse en parte gracias a la comparación con el anatolio, concretamente con los infinitivos y con el caso adlativo en

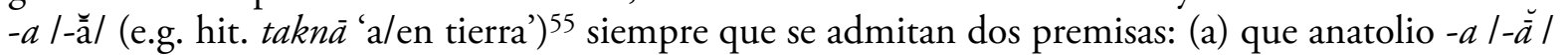
puede retrotraerse a ${ }^{*} /-\mathrm{a}(\mathrm{H}) /\left(\mathrm{de} \mathrm{IE}^{*}-e h_{2}\right)$, (b) que gr. $-\alpha$ refleje indirectamente $* /-\mathrm{aHi} /\left({ }^{*}-e h_{2}-i\right)$, con /-i/ deíctico como recaracterización (como en ved. -sáni) o como confluencia de dat. *-ei (que sería forma heredada, como atestiguan otras lenguas indoeuropeas) con ${ }^{*}-a(H)$, una vez que la gramaticalización del infinitivo se completa en griego y la forma no guarda ya relación ninguna con su función originaria.

Admitidos estos supuestos, es posible suponer que protogr. ${ }^{*}$-menai $\mathrm{y}^{*}$-uenai procedieran de la confluencia de dat. *-men-ei, *-uen-ei y de "adlativo" *-mena $(H)$ (cf. luv. jerogl. -mina) y *-uena $(H)$ (cf. luv. -una), una vez que la diferencia de funciones entre ambas formas había desaparecido en el marco de la completa gramaticalización del infinitivo en griego. Una cuestión que queda, por el momento, abierta es si las formas en ${ }^{*}-a H$ fueron heredadas en griego, es decir, si el caso en ${ }^{*}$-aH $\left({ }^{*}-e h_{2}\right)$, al margen de si era adlativo, adlativo-locativo o perlativo en origen, como sugieren una serie de empleos no adlativos en anatolio, e.g. - a locativo en palaíta úlàna'en la pradera', o en hitita ménahh =anda "into the face" (Nikolaev 2010) o si, por el contrario, representan una isoglosa exclusivamente greco-anatólica que, a su vez, podría reflejar un desarrollo areal o bien la irradiación de un préstamo morfosintáctico del protoanatolio al protogriego ${ }^{56}$. He aquí una cuestión abierta que bien puede cerrar esta relectura de la obra pionera de Franz Bopp.

55 Hit. taknā es ciertamente inseparable de hom.

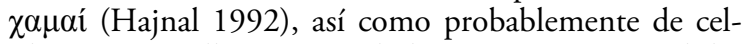
tib. Tamai (Villar 1993, Nikolaev 2010), aunque el detalle de la interpretación de la forma es controvertido.
56 La propuesta entra bien en el marco del contacto lingüístico entre Anatolia y Grecia en la Edad del Bronce y, concretamente, en el modelo de Watkins 2001. 


\section{BibliografíA}

Bopp, F., CS, Über das Conjugationssystem der Sanskritsprache in Vergleichung mit jenem der griechischen, lateinischen, persischen und germanischen Sprache. Nebst Episoden des Ramajan und Mahabharat in genauen metrischen Uebersetzungen aus dem Originaltexte und einigen Abschnitten aus den Veda's. Herausgegeben und mit Vorerinnerungen begleitet von Dr. K. J. Windischmann, Frankfurt am Main: Andreäische Buchhandlung 1816.

—, VG, Vergleichende Grammatik des Sanskrit, Zend, Griechischen, Lateinischen, Litthauischen, Altslawischen, Gotischen und Deutschen (Berlin, 1833, 1835, 1842, 1847, 1849, 1852) 1868 (3.ed.).

Bologna, M. P., 1992, "Il 'dualismo' di Franz Bopp», Incontri Linguistici 15, $29-48$ (Itinerari ottocentistichi tra linguistica storico-comparativa e linguistica generale, Roma 2016, 13-30).

Eichner, H., 1973, «Die Etymologie von heth. mehur», Münchener Studien zur Sprachwissenschaft 31, 53107.

García Ramón, J. L., 1993, "Zur Morphosyntax der passivischen Infinitive im Oskisch-Umbrischen: u. -f(e)i, o. -fir und ursabell. *-fie ${ }^{*}\left({ }^{*}-d^{h} i e h_{1}\right)$ ), Oskisch-Umbrisch: Texte und Grammatik, Fachtagung der Indogermanischen Gesellschaft und der Società Italiana de Glottologia, Freiburg 25-28.9.1971, Wiesbaden, 106-124.

—, 1997, «Infinitive im Indogermanischen? Zur Typologie der Infinitivbildungen und zu ihrer Entwicklung in den älteren indogermanischen Sprachen», Incontri Linguistici 20, 45-69.

—, 2007, "Zur Entstehung und Semantik der Periphrase mit Supinum im Hethitischen», Studi micenei ed egeo-anatolici 49, 281-292.

—, en prensa 1, «Non-finite Verbal Morphology», A. Garret \& M. Weiss (eds.), Handbook of Indo-European Studies, Oxford University Press.

-, en prensa 2, "Heterogeneous correspondences and reconstruction: the gerundive in -mina of Hieroglyphic Luvian", Adjectifs verbaux et participes dans les langues indo-européennes. Arbeitstagung der Indogermanischen Gesellschaft (Paris 24.-26.09.2014).

-, en prensa 3, "Anatolian and Core Indo-European, Anatolian and Greek», Fachtagung Hot Topics in Anatolian Linguistics zu Ehren von Craig Melchert, Innsbruck (30.6-1.7.2016).

Gото̄, T., 2013, Old Indo-Aryan morphology and its Indo-Iranian background (in cooperation with Jared S Klein and Velizar Sadovski), Wien.

Hackstein, O., 2005, «Archaismus oder historischer Sprachkontakt: Zur Frage westindogermanisch-tocharischer Konvergenzen», Sprachkontakt und Sprachwandel (Akten der XI. Fachtagung der Indogermanischen Gesellschaft, Halle an der Saale 17-23.9.2000), Wiesbaden 2005, 169-184.

Hajnal, I., 1992, "Griechisch $\chi \alpha \mu \alpha i ́$ - ein Problem der Rekonstruktion?», Interne Rekonstruktion und relative Chronologie (Akten der VIII. Fachtagung der Indogermanischen Gesellschaft, Leiden, 31.8-4 .9.1987), Innsbruck, 207-220.

Haspelmath, M., 1995, "The converb as a cross-linguistically valid category», in M. Haspelmath, M. and E. König (eds.), Converbs in Cross-Linguistics Perspective, Berlin: Mouton de Gruyter, 1-55.

Hettrich, H., 1984, "Zur historischen Syntax der nomina actionis im Rogveda: Der 'doppelte Dativ'», Münchener Studien zur Sprachwissenschaft 43, 55-106.

Melchert, H. C., 1994, Anatolian Historical Phonology, Atlanta-Amsterdam.

—, 2004, "Hieroglyphic Luvian Verbs in -min(a)», Per aspera ad asteriscos (Studia ... Jens E. Rasmussen), Innsbruck, 356-362.

Morpurgo Davies, A., 1987, “To put” and "to stand” in the Luwian Languages», C. Watkins (ed.), Studies in Memory of Warren Cowgill, Berlin-New York, 205-228.

Nikolaev, A., 2010, "Hittite mënahhanda», Journal of the American Oriental Society 130, 63-71.

Rieken, E., 1999, Untersuchungen zur nominalen Stammbildung des Hethitischen. Wiesbaden.

SEebold, E., 1970, Vergleichendes und etymologisches Wörterbuch der germanischen starken Verben. Paris-Den Haag.

StARKe, F., 1990, Untersuchungen zur Stammbildung des keilschrift-luwischen Nomens, Wiesbaden. 
STRUNK, K., 1977, «Heterogene Entsprechungen zwischen indogermanischen Sprachen», Zeitschrift für Vergleichende Sprachwissenschaft 91, 11-36 (: Kleine Schriften, 457-482).

STÜBER, K., 2009, Der altirische do-Infinitiv - eine verkannte Kategorie, Bremen: Hempen.

VIllar, F., 1993, "Botorrita soz auku aresta [.] [.] tamai», Sprachen und Schriften des antiken Mittelmeerraums. Festschrift für Jürgen Untermann, Innsbruck, 465-471.

Watkins, C., 2001, "An Indo-European linguistic area and its characteristics: Ancient Anatolia», in A. Aikhenvald and R. M. W. Dixon (eds.), Areal Diffusion and Genetic Inheritance, Oxford, 44-63 (Selected Writings, 940-959).

Zehnder, Th., 2011, "Zur Funktion der Infinitive im Veda», Indogermanistik und Linguistik im Dialog (Akten der XIII. Fachtagung der Indogermanischen Gesellschaft, Salzburg). Innsbruck, 622-631. 